\title{
Texan research centre struggles to survive oil money slump
}

\section{Houston, Texas}

A CLUSTER of buildings in a verdant development about 35 miles north of Houston is the home of a new multidisciplinary research institution trying to bring the talents of Texan universities to bear on the needs of industry. Certainly the new centre, called HARC for Houston Area Research Center, has attracted interest. But interest is not money and in the depressed state of the Texan economy, HARC is scrambling to avoid crashing before it can take off.

HARC began in 1982 . The idea was to provide "an innovative research and development environment" that government and industry could take advantage of. As well as developing its own resources, HARC works in liaison with members of the faculty at Rice University, Texas A\&M University, the University of Houston University Park campus and the University of Texas at Austin.

George Mitchell, chairman and president of Mitchell Energy and Develop-

Locust plague ahead?

\section{London}

AnXIETy about a new locust plague in the wake of the impending rainy season in Africa has prompted attempts to resuscitate international programmes for locust control, many of which have been run down or even abandoned in the several years since the last serious plague of locusts in Africa. With the breaking of the African drought in 1985, conditions are now thought to be more favourable for a plague of locusts than at any time for $\mathbf{5 0}$ years. High-density populations of the four species of locusts in Africa are known already to be attacking vegetation.

Preparations to head off what could be a plague affecting the whole of Africa are being coordinated by the Emergency Centre for Locust Operations of the UN Food and Agriculture Organization, which last year raised $\$ 51$ million by an appeal for funds for locust control. This year, \$19 million has been pledged so far, while the British government has promised an extra $£ 7$ million.

Last year's programme of ground and aerial control seems to have headed off what could have been a plague. Small-scale control programmes have already begun, with farmers applying pesticides to protect their ground from newly hatched insects. After the expected rains, control will focus on aerial spraying of large areas. Roger Bone of the Tropical Development and Contol Institute says the situation in Africa is "still dangerous". ment, has provided the inspiration - - and a lot of the cash - to get HARC off the ground. Mitchell is also the driving force behind The Woodlands, the planned community in which HARC is located. In 1984, Mitchell Energy and Development Corporation, The Woodlands Corporation and Mitchell himself together provided HARC with $\$ 2.4$ million, nearly half of HARC's cash income. In 1985, Mitchell's share rose to $\$ 2.6$ million, although total income rose to nearly $\$ 8 \mathrm{mil}-$ lion, mainly because of a Department of Energy contract to the Texas Accelerator Center, one of HARC's eight divisions.

But Department of Energy support for the Texas Accelerator Center has evaporated with the decision to use superconducting magnets, rather than the superferric design developed by the Texas group, for the Superconducting Supercollider (SSC). There is still some bitterness about the magnet selection process. Three completed magnets sit in the centre's workshop, testifying to the feasibility of the design.

Shut out for the time being from SSC projects, the accelerator centre has looked in other directions for financial support. One promising project is to apply the expertise gained in designing the SSC magnets in the design of magnets for magnetic resonance imaging devices (MRI), formerly called nuclear magnetic resonance imagers. HARC has received funds from Baylor College of Medicine to build a magnet for an MRI, and there may be a large commercial market for a new version of the increasingly popular MRIs.

HARC also hopes that its new SX-2 supercomputer, manufactured by Nippon Electronics Corporation (NEC), will enable it to compete for contracts. HARC took delivery of the new computer last summer, and is still working the bugs out of the system.

Even so, HARC has been criticized for deciding to purchase a $\$ 20$-million Japanese supercomputer. HARC's purchase appears to have sparked the trade investigation on the trade in supercomputers launched last year by the US Trade Representative. HARC vice-president for development, Jane Armstrong, says HARC knew it would run into trouble for the decision. But, she says, HARC based its decision on strong commitment from NEC to support it. NEC has already awarded HARC a $\$ 500,000$ contract, and there is promise of more to come.

HARC also believes there is great potential for the future in its Space Technology and Research (STAR) Center; it announced last month that STAR had formed a partnership with Space Industries, Inc. to provide equipment and experiments for the Industrial Space Facility. David Norton, STAR's director, says this agreement will give HARC access to space before the space station is operational. Norton is enthusiastic about the commercial possibilities that a microgravity environment may provide. But no cash will change hands in the deal with Space Industries: HARC will instead receive space on the new facility in exchange for its development efforts.

Perhaps the most promising area for commercial development at HARC comes from the Geotechnology Research Institute and its energetic director Manik

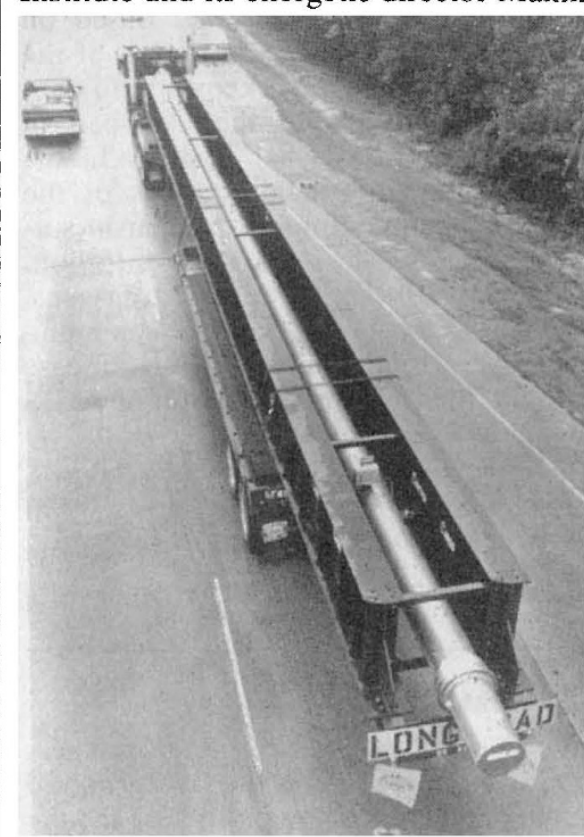

Superferric magnet on its way to storage.

Talwani. Talwani had been director of Columbia University's Lamont-Doherty Geological Observatory and after that director of research for Gulf Oil. He would like to establish an energy research consortium, similar to the electronics industry's Microelectronics and Computer Technology Corporation (MCC). Such a consortium would focus on recovery techniques to bring down the price of recovering oil from fields that have already yielded up their easily retrievable reserves.

Talwani argues that the depressed oil economy may paradoxically help to generate interest in HARC. Oil companies that have had to scale down their own research and development activities may find it cost-effective to contract for such services with HARC. Talwani is also trying to put together a $\$ 22$ million programme for deep reflection profiling on the continental margins. The National Science Foundation is said to be interested.

The depressed oil economy has made Texas industry less willing or able to support new ventures such as HARC. If it can scrape by through the hard times, HARC may nevertheless provide a model for future relations among industry, universities and government.

Joseph Palca 